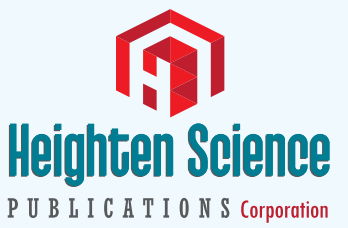

ISSN

2575-0186
*Address for Correspondence: Lai Poh Soon, Forensic Scientific Officer, National Institute of Forensic Medicine, Hospital Kuala Lumpur, Ministry Of Health Malaysia, Malaysia, Tel: 0326906694; Email: roysonn1@hotmail.com

Submitted: 02 January 2018

Approved: 15 January 2018

Published: 17 January 2018

Copyright: @ 2018 Soon LP, et al. This is an open access article distributed under the Creative Commons Attribution License, which permits unrestricted use, distribution, and reproduction in any medium, provided the original work is properly cited.

Keywords: Urinary bladder distension;

Postmortem computed tomography; Alcohol; Toxicology; Drug of abuse

\section{Correlate alcohol and toxicology analysis with Urinary Bladder Distension on Post-mortem Computed Tomography (PMCT): A Validation Study}

\author{
Lai Poh Soon ${ }^{1 *}$, Mohamad Helmee Mohamad Noor², Nor Fadhilah \\ Madon ${ }^{3}$, Mohd Hilmi Saidin', Mansharan Kaur Chainchel Singh ${ }^{4}$ \\ and Kunasilan Subramaniam ${ }^{5}$ \\ 'Forensic Scientific Officer, National Institute of Forensic Medicine, Hospital Kuala Lumpur, \\ Ministry Of Health Malaysia \\ ${ }^{2}$ Forensic Radiologist, Diagnostic Imaging Department, Hospital Kuala Lumpur, Ministry Of \\ Health Malaysia \\ ${ }^{3}$ Forensic Medical Officer, Pathology Department, Hospital Univeristi Kebangsaan Malaysia \\ (HUKM) \\ ${ }^{4}$ Forensic Radiologist, Institute for Pathology, Laboratory and Forensic Medicine, Universiti \\ Teknologi MARA (UiTM) \\ ${ }^{5}$ Forensic Clinical Specialist, National Institute of Forensic Medicine, Hospital Kuala Lumpur, \\ Ministry Of Health Malaysia
}

\section{Abstract}

Urinary bladder distension is traditionally regarded as a sign of intoxication at autopsy, however, to date there is very little literature available to support this hypothesis. The purposes of our study were to correlate alcohol and/or toxicological analysis with calculated urinary bladder volumes and its sensitivity as well as to test the validity by using the radiologically calculated urinary bladder volumes (UBVs) from CT images. The study population was all the postmortem cases involving with blood and/or urine samples sent for alcohol and/or toxicology analysis in 2016 at the Kuala Lumpur Hospital. Out of that 485 cases, there were 127 postmortem cases retrieved with positive alcohol and/or toxicology results Positive toxicology results in this study was referring to drug of abuse (DoA) including amphetamine type stimulants, opiates, cannabis and ketamine. Urinary bladder volume (UBV) was calculated based on the equation used in ultrasonographic volumetry, $\mathrm{V}=\mathrm{axbxcx} 0.5$. These 3 parameters correlated well with the UBV and having a strong positive relationship. There was a significant positive correlation at low strength between alcohol concentrations with calculated UBV. There was statistical significant correlation between urinary bladder distension on postmortem CT and cases of intoxication especially more corresponding for positive alcohol detection. The average sensitivity was $35.65 \%$ whereby it was slightly lower than those reported in Rohner C, et al. In this study we have deduced that diuretics effect of alcohol was the main reason causing bigger urinary bladder or UBV and was more prominent than the influence of drug of abuse on the urinary bladder sphincter. The distension of urinary bladder should raise suspicion of intoxication, but would not provide information on the quantity of the intoxicating agent due to its significant but poor correlation. It was important to note that intoxication may also be present in cases with low urinary bladder volume. In conclusion, it is vital to consider circumstantial evidence, as well as the presence of additional findings on imaging before suggesting the diagnosis of intoxication based on urinary bladder distension on imaging. Currently, the use of CT bladder imaging should serve as a strong indication that the individual may be intoxicated but should be confirmed by a complete autopsy and a detailed toxicological analysis. 


\section{Introduction}

Computed tomography (CT) and magnetic resonance (MR) imaging are gaining acceptance for use in routine forensic investigations but remain challenging in the detection of non-traumatic causes of death. Cases of intoxication are notably not recognized on routine post-mortem imaging. Approximately one third of all cases brought to our institute for medico-legal investigation test positive for alcohol, narcotics, and/or pharmaceutical drugs. Post-mortem imaging is blind to most of these cases although hyper dense residues from tablets occasionally are detected in the gastro-intestinal tract may suggest intoxication as cause of death [1]. Urinary bladder distension is traditionally regarded as a sign of intoxication at autopsy, yet, there is very little literature available to support it [2].

Alcohol and toxicology levels are always associated with fatal accidents, suicide, drowning, trauma deaths, and other violence crimes. Blood alcohol concentrations (BLACs) and toxicology concentrations (TCs) are regularly tendered as evidence in criminal and civil trial. The forensic toxicologist is commonly asked to give an expert opinion on the alcohol or toxicology concentrations measured in postmortem samples during routine work or court testimony. The postmortem interval, the condition of the body and the nature of the collected specimen for analysis are among the important factors to be considered during the interpretation. In order to interpret correctly the detected BLAC and/or TC, it is suggested that several different specimens should be collected and analyzed such as stomach content, bile, vitreous humor, cerebrospinal, and/or urine in addition to blood especially if decomposition is present.

If distension of the urinary bladder were a reliable indicator of intoxication, it would represent a useful radiologic sign on post-mortem imaging because the urinary bladder can be readily identified on cross-sectional imaging. The purposes of our study were to correlate alcohol and/or toxicological analysis with calculated urinary bladder volumes and its sensitivity as well as to test the validity by using the radiologically calculated urinary bladder volumes (UBVs) from CT images.

There was rarely reported literature on the distension of the urinary bladder on PMCT images to correlate the sign of intoxication at autopsy. A study was solely conducted and collaborated between University of Zurich, Switzerland and University of New Mexico, USA in year 2011. The aim of the study was to compare radiologically calculated UBV to autopsy measurements of UBV, and to investigate the relationship between calculated UBV and intoxication. Autopsy reports, toxicology reports and post-mortem CTs of 332 adult human dead bodies were retrospectively analyzed, total of 259 cases were included. Spearman's rho test was used to compare calculated UBV to autopsy measurements as well as to correlate the widest left-right bladder diameter on axial images to calculated UBV. Significance levels for UBV in relation to toxicology results were investigated with the Mann-Whitney test. Both calculated UBV and axial urinary bladder diameter (AUBD) were subjected to receiver operating characteristics curve analysis whereby the sensitivity and specificity were calculated for individual cut-off values [3].

There was a strong correlation and high consistency $(\mathrm{r}=0.92, \mathrm{p}<0.001)$ between the measured and calculated UBV. Hence, radiologically calculated UBV accurately represents the autoptically measured UBV. Positive toxicology results strongly correlate with calculated UBV $(\mathrm{p}<0.001)$. Furthermore, there was also a strong correlation between calculated UBV and AUBD ( $\mathrm{p}<0.001)$. UBV of $>182 \mathrm{ml}$ and $>330 \mathrm{ml}$ indicated positive toxicology results with a sensitivity/specificity of $40 \% / 87 \%$ and $25 \% / 97 \%$ respectively. AUBD of $>8.5 \mathrm{~cm}$ and $>10 \mathrm{~cm}$ indicated positive toxicology results with a sensitivity/specificity of $36 \% / 85 \%$ and $16 \% / 95 \%$ respectively. The authors stated that the occurrence of a distended urinary bladder post-mortem imaging should raise suspicion of intoxication [4]. 
In conjuction with this study, we have applied the cut-off value of $>182 \mathrm{ml}$ for UBV. This study will assist the forensic pathologist and forensic radiologist to raise suspicion of intoxication on the occurrence of urinary bladder distension on postmortem imaging. This radiologically calculated urinary bladder volumes (UBVs) from CT images will be one of the screening methods for intoxication cases.

The general objectives of this study was to correlate intoxication with the urinary bladder distension on PMCT images. The specific objectives were including determine relatedness of urinary bladder volume (UBV) with axial urinary bladder diameter (AUBD); determine relatedness of alcohol concentrations with UBV; assess the significance levels (p) of urinary bladder distension among individual presented with alcohol and/or individual presented with toxicology; and calculate the sensitivity of the positive of the alcohol and/or toxicology results presented with distended urinary bladder at the cut-off points of UBV ( $>182 \mathrm{ml})$.

\section{Methodology}

This was a retrospective cross-sectional study. The study population involved individuals that under vent a complete postmortem examination followed by a toxicological analysis of the blood and/or urine samples sent for alcohol and/or toxicology analysis in 2016 at the Kuala Lumpur Hospital. Inclusion criteria were cases with a postmortem examination with a positive alcohol and/or toxicology results. Radiological images from postmortem CT scan with 64 slices were retrieved for all the cases and those unavailable cases were excluded. We have excluded all the decomposed bodies and cases with ruptured urinary bladder.

The positive results of the alcohol and/or toxicology (including any of the opiates, amphetamine-type of stimulants, ketamine and cannabis) were retrieved from the postmortem results database system from year 2016. Urinary bladder distension was evaluated based on the bladder diameter measurements including maximal leftright diameter ("a") on the original axial images and maximal cranio-caudal ("b") and anterior-posterior diameter ("c") on multiplanar reformatted (MPR) sagittal images, always measuring in the midsagittal plane by using OsiriX software in PMCT terminal (Figure 1). The pubic symphysis was used as reference point anteriorly. Urinary bladder volume (UBV) was calculated based on the equation used in ultrasonographic volumetry, $\mathrm{V}=$ axbxcx 0.5 [4]. UBV was then correlated with AUBD using statistical Spearman's rho test. Alcohol concentrations in blood and/or urine specimen were subsequently correlated with UBV using statistical Spearman's rho test. Kruskal-Wallis test was used to assess the significance levels (p) of urinary bladder distension among individual presented with alcohol and individual presented with toxicology as well as individual with both alcohol and toxicology presented.

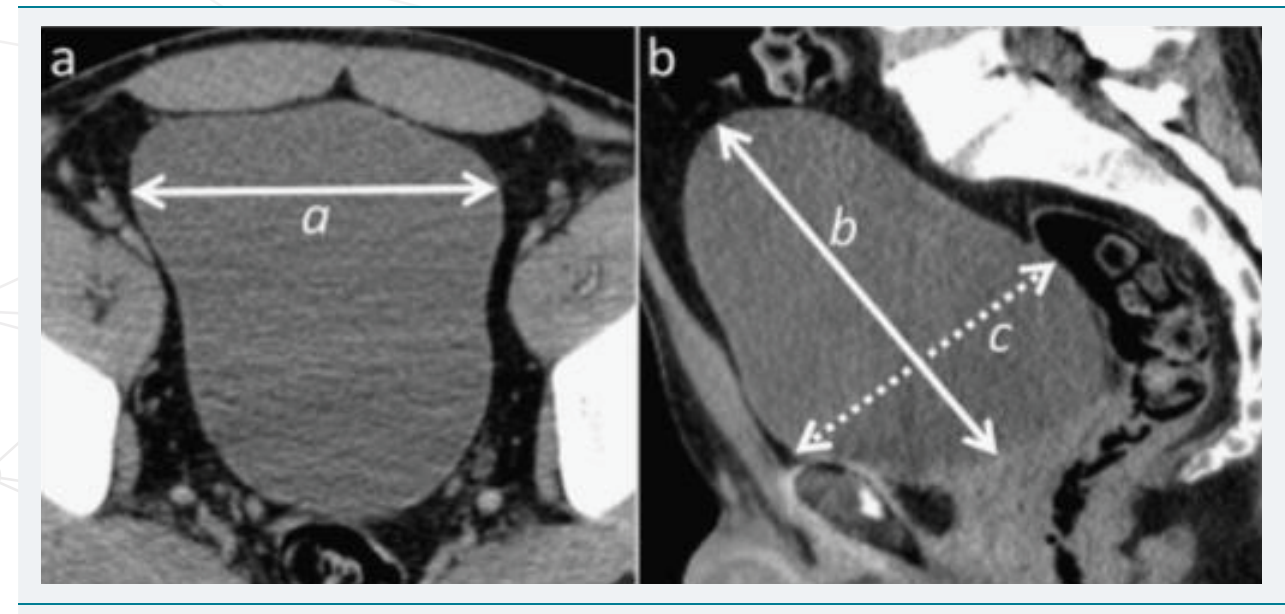

Figure 1: Measurements of the parameters. 
The study population was subsequently divided in 2 main groups: bladder distended individuals with UBV $>182 \mathrm{ml}$; and non-bladder distended individuals with UBV $\leq 182 \mathrm{ml}$. Sensitivity of the positive of the alcohol and/or toxicology results presented with distended urinary bladder at the cut-off points of UBV was calculated. No ethical approval was required as only patients data were utilized without any clinical intervention and only retrospective data retrieved for analysis.

\section{Results}

A total of 485 cases were identified that undervent a postmortem examination and toxicological analysis of the blood and/or urine samples in year 2016 at the Kuala Lumpur Hospital. Out of that, there were 127 postmortem cases retrieved with positive alcohol and/or toxicology results whereby 5 were females and 122 were males resulting in a female to male ratio of 1:24.4 compared to common postmortem gender ratio in our institute averaging 1:5.8. The study population average age was 38.53 years old with a range of 17-74 year old with majority in the age group of 31-40 years old (29.1\%). The UBV was calculated from the 3 parameters of maximal leftright diameter ("a") on the original axial images and maximal cranio-caudal ("b") and anterior-posterior diameter ("c") on multiplanar reformatted (MPR) sagittal images. The calculated UBV ranged from 17.38-704.73 ml with average of $147.71 \pm 126.48$ $\mathrm{ml}$ (Table 1). These 3 parameters correlated well with the UBV and having a strong positive relationship. They also have true correlation among one another. This study concurred with the findings by C. Rohner et al. (2013) where AUBD have the highest strength of positive relationship with calculated UBV at $r=9.939, p<0.001$, followed by parameter $C$ at $r=9.934, p<0.001$ (Table 2) [3]. There was a significant positive correlation at low strength between alcohol concentrations with calculated UBV. The relationships were represented as $r=0.279, p<0.01$ in blood specimen and $r=0.348$, $\mathrm{p}<0.01$ in urine specimen.

In addition, there was significant difference of alcohol detection in blood especially at low alcohol concentration $<200 \mathrm{mg} / 100 \mathrm{ml}$ (Table 3) between UBV categories at cutoff point of $182 \mathrm{ml}$, represented as $\chi^{2}(1, \mathrm{~N}=126)=3.933, \mathrm{p}<0.05$. In rough estimation, there was about $80.4 \%$ of the negative blood alcohol concentration (BAC) with UBV below $182 \mathrm{ml}$, however, the actual sensitivity was in fact only $36.5 \%$ of the positive

\begin{tabular}{|c|c|c|c|c|}
\hline \multicolumn{2}{|l|}{ Table 1: Descriptive Statistics of Parameters. } \\
\hline Parameters & Minimum & Maximum & Mean & Std Deviation \\
\hline a (AUBD), cm & 2.98 & 10.74 & 6.89 & 1.95 \\
\hline B, cm & 2.65 & 14.93 & 6.43 & 2.01 \\
\hline C, cm & 2.19 & 10.44 & 5.42 & 1.96 \\
\hline UBV, $\mathrm{ml}$ & 17.38 & 704.73 & 147.71 & 126.48 \\
\hline BAC, $\mathrm{mg} / 100 \mathrm{ml}$ & 0.0 & 569.0 & 102.9 & 120.9 \\
\hline UAC, $\mathrm{mg} / 100 \mathrm{ml}$ & 0.0 & 750.0 & 185.3 & 294.4 \\
\hline
\end{tabular}

\begin{tabular}{|c|c|c|c|c|c|c|}
\hline & & & AUBD & b & c & UBV \\
\hline \multirow{12}{*}{ Spearman's rho } & \multirow{3}{*}{ AUBD } & Correlation Coefficient & 1.000 & $.776^{\star *}$ & $.847^{\star \star}$ & $.939^{* *}$ \\
\hline & & Sig. (2-tailed) & . & .000 & .000 & .000 \\
\hline & & $\mathrm{N}$ & 127 & 127 & 127 & 127 \\
\hline & \multirow{3}{*}{ b } & Correlation Coefficient & $.776^{\star *}$ & 1.000 & $.687^{\star *}$ & $.869^{* *}$ \\
\hline & & Sig. (2-tailed) & .000 & . & .000 & .000 \\
\hline & & $\mathrm{N}$ & 127 & 127 & 127 & 127 \\
\hline & \multirow{3}{*}{ c } & Correlation Coefficient & $.847^{\star *}$ & $.687^{\star \star}$ & 1.000 & $.934^{* *}$ \\
\hline & & Sig. (2-tailed) & .000 & .000 & . & .000 \\
\hline & & $\mathrm{N}$ & 127 & 127 & 127 & 127 \\
\hline & \multirow{3}{*}{ UBV } & Correlation Coefficient & $.939^{* *}$ & $.869^{* *}$ & $.934^{* *}$ & 1.000 \\
\hline & & Sig. (2-tailed) & .000 & .000 & .000 & . \\
\hline & & $\mathrm{N}$ & 127 & 127 & 127 & 127 \\
\hline
\end{tabular}


BAC with UBV above $182 \mathrm{ml}$. Again, there was a significant positive correlation at low strength $(\mathrm{r}=0.177, \mathrm{p}=0.048)$ between $\mathrm{BAC}$ with calculated UBV categories at cut-off $182 \mathrm{ml}$.

Furthermore, there was also significant difference of urine alcohol detection especially at low UAC $100-200 \mathrm{mg} / 100 \mathrm{ml}$ (Table 4 ) between UBV categories at cutoff point of $182 \mathrm{ml}$, represented as $\chi^{2}(1, \mathrm{~N}=74)=7.433, \mathrm{p}<0.05$. There was estimated roughly $80.0 \%$ of the negative urine alcohol concentration (UAC) with UBV below 182 $\mathrm{ml}$, however, the actual sensitivity was computed at $49.1 \%$ of the positive urine alcohol concentration with UBV above $182 \mathrm{ml}$. We have discovered also a significant positive correlation at higher strength $(\mathrm{r}=0.317, \mathrm{p}<0.01)$ between UAC with calculated UBV categories at cut-off $182 \mathrm{ml}$ comparing with BAC with the same UBV cut-off.

There was even lower sensitivity of blood toxicology (19.0\%) and urine toxicology (25.8\%) detection between the UBV categories of cut-off point at $182 \mathrm{ml}$ (Table 5). It has revealed that blood toxicology was not statistically in difference between the categories, represented as $\chi^{2}(1, N=123)=2.773, p>0.05$ and not correlated statistically as well at $r=-0.150, p>0.05$ (Table 9). On the other hand, urine toxicology was statistically in difference between the categories, represented as $\chi^{2}(1, N=81)=4.639$, $\mathrm{p}<0.05$ and also negative correlated statistically at lower strength with $r=-0.239$, $<0.05$.

In a summary of the results, the overall sensitivity of both alcohol and/or toxicology detection at the UBV cut-off point of $182 \mathrm{ml}$ in blood specimen and urine specimen were $29.0 \%(31 / 107)$ and $42.3 \%(30 / 71)$ respectively (Tables 6,7). The average sensitivity was $35.65 \%$ whereby it was slightly lower than those reported in Rohner C et al. [3].

By using Kruskal-Wallis test, those cases of positive alcohol detected were presented with bigger urinary bladder compared to cases of positive toxicology, statistically significant at $\mathrm{p}<0.05$ for both urine and blood categories. Those cases with positive alcohol and/or toxicology in urine has bigger urinary bladder comparing with those in blood (Table 8).

Table 3: Blood Alcohol Concentration (BAC) at cut-off UBV $182 \mathrm{ml}$

\begin{tabular}{|c|c|c|c|c|c|c|}
\hline UBV ml & $1-100 \mathrm{mg} / 100 \mathrm{ml}$ & $101-200 \mathrm{mg} / 100 \mathrm{ml}$ & $201-300 \mathrm{mg} / 100 \mathrm{ml}$ & $301-400 \mathrm{mg} / 100 \mathrm{ml}$ & $>400 \mathrm{mg} / 100 \mathrm{ml}$ & Total \\
\hline$>182$ & 5 & 10 & 9 & 2 & 1 & 27 \\
\hline$\leq 182$ & 17 & 15 & 10 & 5 & 1 & 47 \\
\hline Total & 22 & 25 & 19 & 7 & 2 & 74 \\
\hline
\end{tabular}

Table 4: Urine Alcohol Concentration (BAC) at cut-off UBV $182 \mathrm{ml}$.

UBV ml $1-100 \mathrm{mg} / 100 \mathrm{ml} 101-200 \mathrm{mg} / 100 \mathrm{ml} 201-300 \mathrm{mg} / 100 \mathrm{ml} 301-400 \mathrm{mg} / 100 \mathrm{ml}>400 \mathrm{mg} / 100 \mathrm{ml}$ Total

\begin{tabular}{|l|l|l|l|l|l|l|}
\hline$>182$ & 4 & 7 & 9 & 3 & 3 & 26 \\
\hline$\leq 182$ & 5 & 4 & 8 & 4 & 2 & 27 \\
\hline Total & 9 & 11 & 17 & 7 & 5 & 53 \\
\hline
\end{tabular}

Table 5: Urine Alcohol Concentration (BAC) at cut-off UBV $182 \mathrm{ml}$.

\begin{tabular}{|c|c|c|}
\hline UBV & DoA detected in Blood & DoA detected in Urine \\
\hline$>182 \mathrm{ml}$ & 8 & 8 \\
\hline$\leq 182 \mathrm{ml}$ & 34 & 23 \\
\hline Total & 42 & 31 \\
\hline
\end{tabular}

Table 6: Sensitivity of blood toxicology and/or alcohol detection at UBV cut-off $182 \mathrm{ml}$.

\begin{tabular}{|c|c|c|c|c|}
\hline UBV & $\begin{array}{c}\text { DoA Detected } \\
\text { Alcohol } \\
\text { Not Detected }\end{array}$ & $\begin{array}{c}\text { Alcohol Detected } \\
\text { DoA } \\
\text { Not Detected }\end{array}$ & $\begin{array}{c}\text { DoA and Alcohol } \\
\text { Detected }\end{array}$ & Total \\
\hline$>82 \mathrm{ml}$ & 6 & 23 & 2 & 31 \\
\hline$\leq 182 \mathrm{ml}$ & 30 & 43 & 3 & 76 \\
\hline Total & 36 & 66 & 5 & 107 \\
\hline
\end{tabular}




\begin{tabular}{|c|c|c|c|c|}
\hline \multicolumn{2}{|c|}{ Table 7: Sensitivity of urine toxicology and/or alcohol detection at UBV cut-off $182 \mathrm{ml}}$. \\
\hline UBV & $\begin{array}{c}\text { DoA Detected } \\
\text { Alcohol } \\
\text { Not Detected }\end{array}$ & $\begin{array}{c}\text { Alcohol Detected } \\
\text { DoA } \\
\text { Not Detected }\end{array}$ & DoA and Alcohol Detected & Total \\
\hline$>182 \mathrm{ml}$ & 4 & 22 & 4 & 30 \\
\hline$\leq 182 \mathrm{ml}$ & 19 & 20 & 2 & 41 \\
\hline Total & 23 & 42 & 6 & 71 \\
\hline
\end{tabular}

\begin{tabular}{|c|c|c|c|c|}
\hline \multicolumn{4}{|l|}{ Table 8: Descriptive Statistics of UBV according to Categories. } \\
\hline UBV, ml & Minimum & Maximum & Mean & Std Deviation \\
\hline Blood_Positive DoA & 17.38 & 430.06 & 117.36 & 113.61 \\
\hline Blood_Positive_Alcohol & 18.63 & 704.73 & 168.84 & 138.64 \\
\hline Urine_Positive DoA & 29.84 & 352.01 & 148.94 & 88.36 \\
\hline Urine_Positive_Alcohol & 39.02 & 704.73 & 226.98 & 134.88 \\
\hline
\end{tabular}

\section{Discussion and Conclusion}

Investigations by Rohner $\mathrm{C}$ et al. [3], have confirmed and proved that methodology used in ultrasonographic urinary bladder volumetry using the formula $\mathrm{V}=\mathrm{axbxcx} 0.5$ as valid for CT volumetry and also applicable to several cross sectional imaging modalities including MRI [3]. They also revealed that there was a high correlation and overall consistency between calculated urinary bladder volumes and measured volumes during autopsy procedures whereby both were differed by less than $25 \mathrm{ml}$. This might be due to partial evacuation of the bladder can be observed when a cadaver was moved from a gurney to a CT table or an autopsy table, hence, the measured UBV was lower than the calculated volume.

In this study we have deduced that diuretics effect of alcohol was the main reason causing bigger urinary bladder or UBV and was more prominent than the influence of drug of abuse on the urinary bladder sphincter. However, we concurred with the findings by Rohner $\mathrm{C}$ et al. [3], that it was not possible to identify individual intoxicating substances based on the volume of urinary bladder on postmortem [3].

There was statistical significant correlation between urinary bladder distension on postmortem CT and cases of intoxication especially positive alcohol detection. However, the average sensitivity was $35.65 \%$ whereby it was slightly lower than the $40 \%$ as reported by Rohner $C$ et al. [3], assuming that the specificity of $87 \%$ did not changed at the cut-off point of $182 \mathrm{ml}$ conveyed by them because our study only included postmortem cases with positive alcohol and/or toxicology results [3]. Hence, it was important to note that intoxication may also be present in cases with low urinary bladder volume. These findings stand in agreement with the general opinion of forensic pathologists on this subject according to Uchigasaki $S$ et al. [2]. One of the reasons was the seizures can occur as a consequence of intoxication and may also induce bladder evacuation.

Our study has several limitations that deserve attention and comments. First, this was the validation study of the findings and method used by Rohner C et al. [3], and hence we only included those postmortem cases presented with positive alcohol and/ or toxicology results [3]. Second, the quantity of the substances that was detected by toxicological analysis depends on complex interactions, including individual metabolic rates, increased tolerance to a substance, time interval since ingestion, length of the agony and postmortem interval. As such, the distension of urinary bladder should raise suspicion of intoxication, but would not provide information on the quantity of the intoxicating agent due to its significant but poor correlation. In conclusion, it is vital to consider circumstantial evidence, as well as the presence of additional findings on imaging before suggesting the diagnosis of intoxication based on urinary bladder distension on imaging. 
Aside from the above cited limitations it is important to point out that first the vast majority of Medical Examiner/Coroner's Office around the world lack the funding to have access to CT equipment. While, imaging techniques can serve a supportive role in the investigation there is no substitute to conducting a complete postmortem examination, collection of body fluids, and toxicological analysis to determine the Cause and Manner of Death.

\section{Acknowledgement}

The authors thank the Director General of Health Malaysia for his permission to publish this article. Also we would like to express our appreciation to the Director of Hospital Kuala Lumpur and Director of National Institute of Forensic Medicine, Malaysia for allowing the use of resources throughout the study.

\section{References}

1. Aghayev E, Jackowski C, Christe A, Thali MJ. Radiopaque stomach contents in postmortem CT in suicidal oral medication intoxication: report of three cases. J Forensic Leg Med. 2010; 17: 164-168. Ref.: https://goo.gl/CnM9eb

2. Uchigasaki S, Lach $\mathrm{H}$, Oesterhelweg L, Sperhake JR, Puschel $\mathrm{K}$, et al. Postmortem measurement of the urine volume by ultrasonography. Rechtsmedizin. 2003; 13: 371-374.

3. Rohner C, Franckenberg S, Schwendener N, Oestreich A, Kraemer T, et al. New evidence for old lore-Urinary bladder distension on post-mortem computed tomography is related to intoxication. Forensic Sci Int. 2013; 225: 48-52. Ref.: https://goo.gl/1EFyvT

4. Hofer M. Ultrasound Teaching Manual: The Basics of Performing and Interpreting Ultrasound Scans. Thieme Stuttgart. 2000; 35: 81-82. Ref.: https://goo.gl/hqfA8j 